\title{
Experimental Study on Load-Settlement Behaviour of Cement Stabilised Footing with Different Dimensions on Sandy Soil
}

\author{
Reza Alijani Shirvani · Issa Shooshpasha
}

Received: 19 October 2013 / Accepted: 31 August 2014 / Published online: 6 December 2014

(C) The Author(s) 2014. This article is published with open access at Springerlink.com

\begin{abstract}
Laboratory tests were done to study the loadsettlement behaviour. These tests evaluated rigid square footing on sandy soil and a layered system, stabilised with different dimensions and different cement contents. Nineteen plate load tests were done to make evaluations. The soil type used in tests was poorly graded sand in a box container with the following dimensions; cross section $130 \mathrm{~cm} \times 130 \mathrm{~cm}$ and depth $100 \mathrm{~cm}$. The soil was compacted in layers $10-\mathrm{cm}$ thick. Cement was added in percentages of $2.5,5$ and $7.5 \%$ by dry weight of soil. Samples were cured for 28 days, after which they were tested. Experimental data demonstrated effectiveness in terms of increasing bearing capacity and reducing settlement of the stabilised soil-cement layers. Results also showed difference in terms of crack propagation mechanism between samples with different cement contents as evaluations of number and direction. The load-time curves determined from test data showed that the required time to make constant the load variation versus time was more in those samples with $7.5 \%$ cement content compared to those with cement contents of 2.5 and $5 \%$.
\end{abstract}

Keywords Stabilisation - Lime Portland cement .

Plate load test . Ultimate bearing capacity

\section{Introduction}

The considerations that high-quality materials are increasingly difficult to access and cost of such materials has

R. A. Shirvani $(\bowtie) \cdot$ I. Shooshpasha

Faculty of Civil Engineering,

Babol University of Technology, Babol, Iran

e-mail: R_Alijani_Sh@yahoo.com

I. Shooshpasha

e-mail: shooshpasha@nit.ac.ir increased require that engineers use local soil. In many cases, ground improvement using local soil has shown satisfactory behaviour in many conditions. Ground improvement can be defined as the procedure undertaken to increase parameters of shear strength and to reduce permeability and compressibility of the soil. There are several different methods available to improve the geotechnical properties of problematic soil, one of which is the use of additives. Stabilisation can be achieved by addition of appropriate percentages of cement, lime, fly ash, bitumen, or combinations of these materials to the soil. Selections of type and determination of the percentage of an additive are made according to the soil classification and the degree of soil improvement that is required [1].

Sandy soil covers widespread areas of northern Iran. Liquefaction, low bearing capacity, high potential of failure, high groundwater table and variations in soil density and strength in different places create major problems with infrastructure and construction in such areas [2]. Several methods are applicable for overcoming these problems, one of which is soil stabilisation. Soil stabilisation with cement is an attractive technique in terms of cost and environmental impact as it avoids extracting and transporting materials from elsewhere.

Cemented sand is found in a wide range of materials. It has the behavioural characteristics of both soil and rock, often simultaneously [3]. Artificially cemented soils increase bearing capacity and decrease settlement of the foundations, which are the two major design considerations. Also, cohesion of cemented sandy soil means that it can tolerate stresses caused by tension as well as compressive and shear stress [4]. These advantages determine that artificially cemented soil is increasingly being used in various construction activities; for example, stabilisation of soil beneath foundations of major structures, such as stabilisation of roadbeds, quays and retaining walls. 
Stefanoff et al. [5] suggested that bearing capacity can be increased by using stabilised layers with cemented agents as top layers on a natural soil deposit with low bearing capacity and that such structure will reduce foundation settlement. Elsand et al. [6] assessed foundation settlement on calcareous sandy soil by plate load tests through circular and ring plates. Results showed that less settlement occurred under ring plates than did under circular ones. Esmael and Al-sanad [7] carried out some plate load tests on samples of desert sand that had been slightly cemented. In all tests, punching failure mechanism was observed.

The findings of the conducted plate load tests by Esmael [8] on very dense cemented sand samples by circular and ring plates demonstrated that the settlement of the ring plates was less than that of the circular ones under all tested levels of pressure, while the difference observed between bearing capacity values was negligible in both circular and ring plates. Consoli et al. [9] reported that application of a cemented top layer, in addition to increasing bearing capacity and decreasing settlement of the foundations, served to change soil behaviour to noticeably more brittle behaviour in comparison with natural soil deposits.

Thome et al. [10] suggested a method for predicting the behaviour of shallow foundations on a cemented top layer situated on a lower layer of weakly residual soil. The method was validated by numerical simulation and finally presented a semi-empirical method for designing shallow foundations on a double-layered system. Consoli et al. [11] conducted plate load tests on soil layers compacted with lime and fly ash; in addition to an increase in bearing capacity and reduction in settlement, results were compared with existing theoretical relationships in order to achieve the ultimate bearing capacity of foundations on layered soils, such as Vesic, MeyerhofHanna and Thome relationships, and concluded that Vesic and Thome relationships better predicted ultimate bearing capacity of layered systems on a residual soil deposit for H/D $\leq 1$ ( $\mathrm{H}$ and $\mathrm{D}$ stand for stabilised layer thickness and foundation diameter, respectively). Consoli et al. [12] performed plate load tests on a cemented soil layer situated on a weak deposit and reported that the process of failure in the top layer began with tensile cracks at the end of the stabilised layer.

This study presents an effective method for overcoming construction problems on sandy soil with low bearing capacity in which stabilisation is made on a limited part of the soil beneath the foundation with lime Portland cement, and then, a shallow foundation layer is constructed on this stabilised region. The ultimate bearing capacity or the maximum amount of load that soil can tolerate before shear failure is a criterion used to determine effectiveness of this method. Bearing capacity is defined as the capacity of an underlying soil and foundation to support applied loads to the ground without undergoing shear failure and without occurrence of major settlement $[13,14]$.

\section{Laboratory Model}

A special device was constructed to study the effects of cement treatment on ultimate bearing capacity of sandy soil. The apparatus consisted of a loading frame and a chamber.

\subsection{Loading Frame}

The loading frame consisted of a foundation, columns and a main beam designed for the maximum load of 40 tons to establish certainty with enough strength to provide the predicted reaction load.

\subsection{Test Chamber}

The chamber applied to these experiments consisted of a cube with the dimensions $130 \mathrm{~cm} \times 130 \mathrm{~cm} \times 100 \mathrm{~cm}$ constructed as a network of rectangular HSS with 1-cm-thick Plexiglas walls to make the inside visible. Figure 1 shows the loading frame and the test chamber.

Laboratory plate load tests were performed using the above-mentioned device and a hydraulic jack with the appropriate capacity to maintain the maximum predicted load, concrete footings (that can be cast-in-situ) with the dimensions $10 \mathrm{~cm} \times 10 \mathrm{~cm} \times 10 \mathrm{~cm}$ and to provide the required rigidity and prevent deformation during loading; pressure gauges with the capacity of 10, 60 and 160 bar for taking load measurement, three dial gauges with range of accuracy of 0.01 and $30 \mathrm{~mm}$ travel for taking measurements of settlement, reference beams, etc. The most important reasons for choosing plates of $10 \mathrm{~cm} \times 10 \mathrm{~cm}$ dimensions were as follows:

- Good conformity of laboratory experiments with real results on site.

- No interference of stress path with the chamber walls.

- Performance considerations in laboratory conditions such as space restrictions, limited dimensions of the chamber, weight and volume of tested soil.

\section{Materials}

The soil used in the present study was obtained from the shores of the Caspian Sea (from the city of Mahmoud-Abad, northern Iran). Grain size distribution of the sand is shown in Fig. 2, and it was determined using ASTM D-421 and $422[15,16]$. The sand was classified as fine-grained, poorly graded sand (SP) according to the Unified Soil Classification System [17], as shown in Table 1.

Lime Portland cement was used in these tests. The most important reasons for choosing this kind of cement for the stabilisation agent than ordinary Portland cement were in order to increase initial resistance, decrease sensitivity and better 

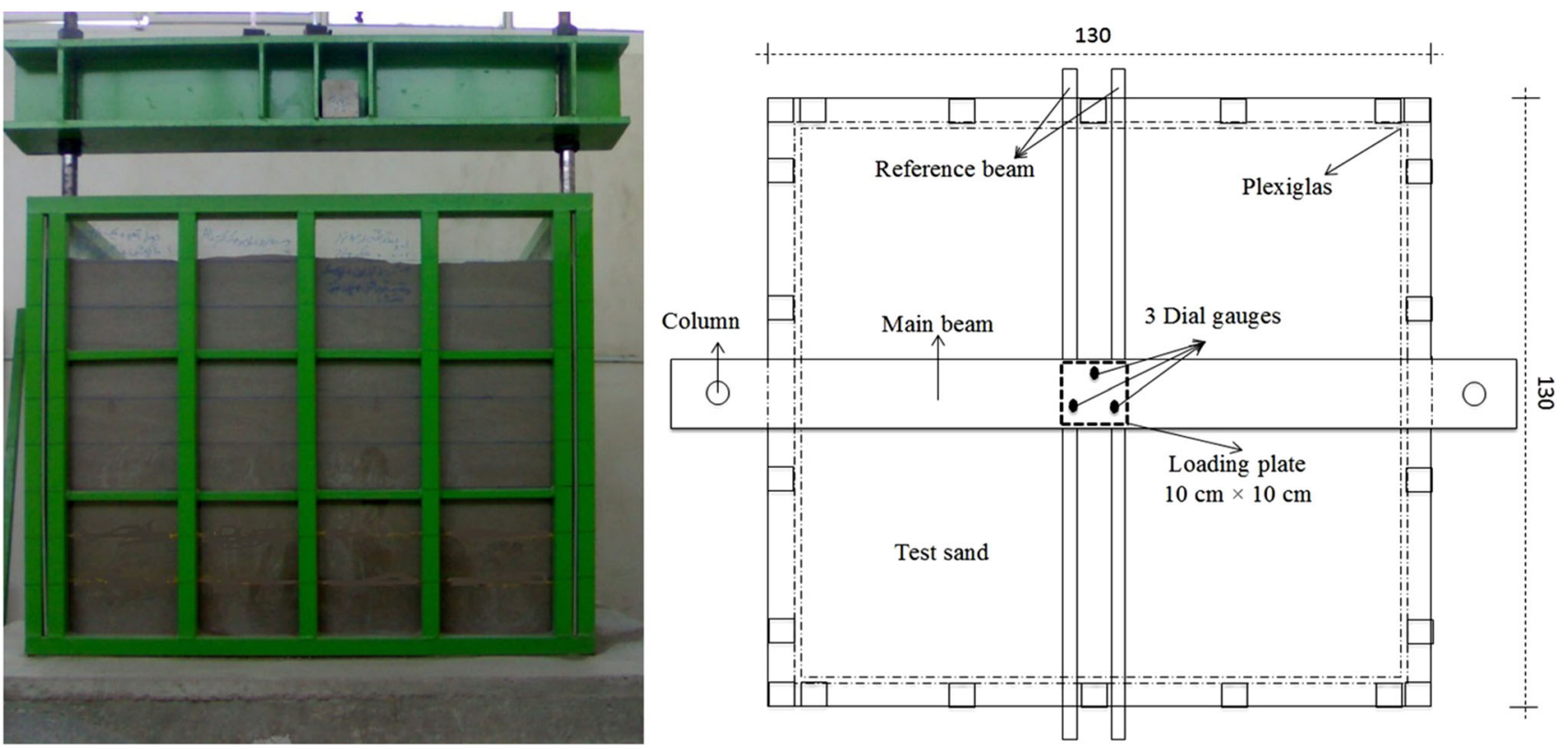

Fig. 1 General test set-up: loading frame with test chamber

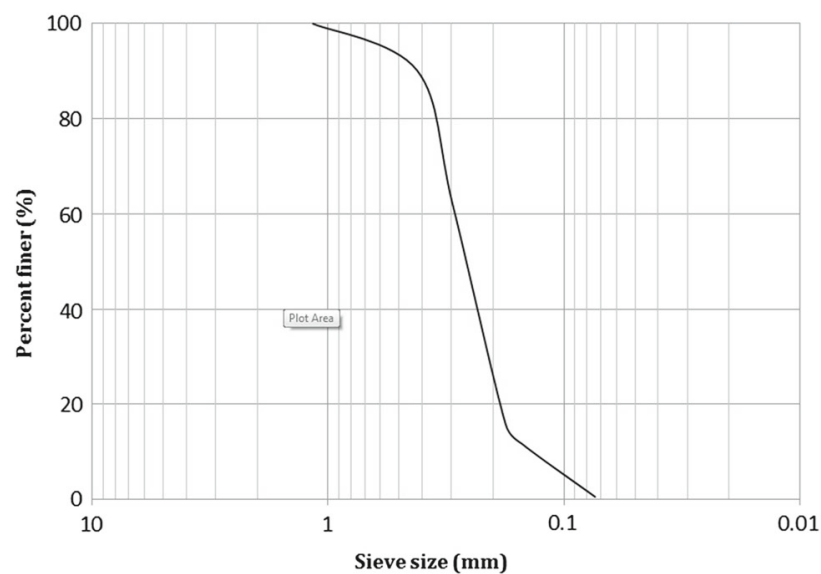

Fig. 2 Grain size distribution curve for Mahmoud-Abad sand

workability. Some of the most important physical characteristics of this type of cement are tabulated in Table 2 [18].

\section{Test Procedures}

In the present study, 18 samples were prepared in order to obtain reliable results. All specimens were prepared at the maximum dry unit weight and optimum moisture content, corresponding to the values obtained from standard Proctor compaction tests made for both cemented and uncemented soil samples [19] (see Sect. 5.1). Table 3 shows characteristics of the soil samples, such as thickness and dimensions.

\subsection{Mixing and Preparation of Samples}

The soil and cement samples were mixed thoroughly until a uniform colour was achieved, and then, the optimum water content was added to each sample. Each specimen for the test was prepared according to optimum water content and maximum dry unit weight. The amount of cement for each mixture was calculated according to the evaluation for dry weight of soil. Specimens were compacted in three identical layers so that each layer achieved the maximum dry unit weight obtained from the compaction test. All samples were prepared in a separate room in a constant temperature.

Mixing and compaction took less than an hour to complete, and this was a shorter duration than the initial setting time, usual for this kind of cement (75 min). Finally, specimens were loaded after a 28-day curing duration.

It is noteworthy that the technique of undercompaction proposed by Ladd [20] was not utilised here for making samples because samples were made at maximum dry unit weight. Baldi et al. [21] reported that application of such a technique was only necessary for specimens with low relative density $(20 \%)$.

\subsection{Compaction of Soil in the Chamber}

A large chamber was used in this present study, so compaction of the soil and obtaining the desirable unit weight, which is the natural dry unit weight of the soil $\left(\gamma_{\mathrm{d}}=\right.$ $16.4 \mathrm{kN} / \mathrm{m}^{3}$ ) [22], was a challenging task. Different methods of soil compaction were examined, and the following 
Table 1 Properties of Mahmoud-Abad sand

\begin{tabular}{lllllll}
\hline $\begin{array}{l}\text { Effective grain } \\
\text { size }\left(\mathrm{D}_{10}\right)\end{array}$ & $\left(\mathrm{D}_{30}\right)$ & $\begin{array}{l}\text { Medium grain } \\
\text { size }\left(\mathrm{D}_{50}\right)\end{array}$ & $\left(\mathrm{D}_{60}\right)$ & $\begin{array}{l}\text { Coefficient } \\
\text { of uniformity }\left(\mathrm{C}_{\mathrm{u}}\right)\end{array}$ & $\begin{array}{l}\text { Coefficient } \\
\text { of curvature }\left(\mathrm{C}_{\mathrm{c}}\right)\end{array}$ & $\begin{array}{l}\text { Specific gravity } \\
\text { of solids }\left(\mathrm{G}_{\mathrm{s}}\right)\end{array}$ \\
\hline $0.15 \mathrm{~mm}$ & $0.21 \mathrm{~mm}$ & $0.27 \mathrm{~mm}$ & $0.29 \mathrm{~mm}$ & 1.93 & $\begin{array}{l}\text { Angle of internal } \\
\text { friction }(\text { in the } \\
\text { densest condition) }\end{array}$ \\
\hline
\end{tabular}

Table 2 Physical properties of lime Portland cement

\begin{tabular}{|c|c|c|c|c|c|}
\hline Specific surface $\left(\mathrm{cm}^{2} / \mathrm{g}\right)$ & Autoclave expansion (\%) & Initial setting $(\mathrm{min})$ & \multicolumn{3}{|c|}{ Compressive strength $\left(\mathrm{kg} / \mathrm{cm}^{2}\right)$} \\
\hline \multirow[t]{2}{*}{$>3,000$} & $<0.8$ & $>75$ & 3 days & 7 days & 21 days \\
\hline & & & $>120$ & $>200$ & $>330$ \\
\hline
\end{tabular}

Table 3 Sample characteristics

\begin{tabular}{|c|c|c|c|c|}
\hline Dimensions $(\mathrm{cm})$ & \multicolumn{3}{|c|}{ Thickness $(\mathrm{cm})$} & Cement percentage \\
\hline $10 \times 10$ & 10 & - & - & $2.5,5$ and 7.5 \\
\hline $20 \times 20$ & 10 & 20 & - & \\
\hline $30 \times 30$ & 10 & 20 & 30 & \\
\hline
\end{tabular}

was determined as the most suitable for the requirements of this investigation.

Height of the chamber $(100 \mathrm{~cm})$ was divided into 10 equal strips so that the soil in each layer (i.e. $10 \mathrm{~cm}$ thick) was compacted separately. The soil weight required in each layer was determined from considerations of soil unit weight and chamber's volume. Soil was transferred in the required amount for each layer, and any unevenness on its surface was smoothed and then the soil was compacted by a metal tamper with an approximate weight of $10 \mathrm{~kg}$ (The tamper comprised of a shaft connected to a $20 \mathrm{~cm} \times 20 \mathrm{~cm}$ square plate attached to its end). In order to control unit weight of the soil, some small dishes were placed at different levels during the process of pouring sand into the chamber. Before each new test, soil was extracted from the chamber and refilled. The procedure described above was also followed for each of the variations of soil density during loading.

The procedure for inserting the sample into the chamber is as follows: The sample is placed inside the chamber based on its height. The soil around the sample is pounded to the top of sample in 10-cm layers to maintain the density and specific gravity.

\subsection{Manner of Load Application}

Tests were done using the stepwise displacement-controlled loading scheme. According to this method, load was applied incrementally to the soil corresponding to settlement increments of approximately $0.5 \%$ of the plate diameter (also in square plates). After application of each settlement increment, load was measured at fixed time intervals; for example, $30 \mathrm{~s}, 1,2,4,8$ and $15 \mathrm{~min}$, after load application until variation of the load ceased. If a constant load is not reached, more time can be used to fix the load. It is important to note that the time pattern used to record the amount of load must be applied at all stages of loading. In this study, each test was continued until a peak load was reached or until the ratio of load increment to settlement increment reached its minimum, steady value [23].

\section{Tests Results and Interpretation}

\subsection{Compaction Tests}

Standard compaction tests were performed on both cemented and uncemented soil samples to investigate optimum moisture content and maximum dry unit weight in accordance with ASTM D-698, including the A method. Results of compaction tests are shown in Fig. 3.

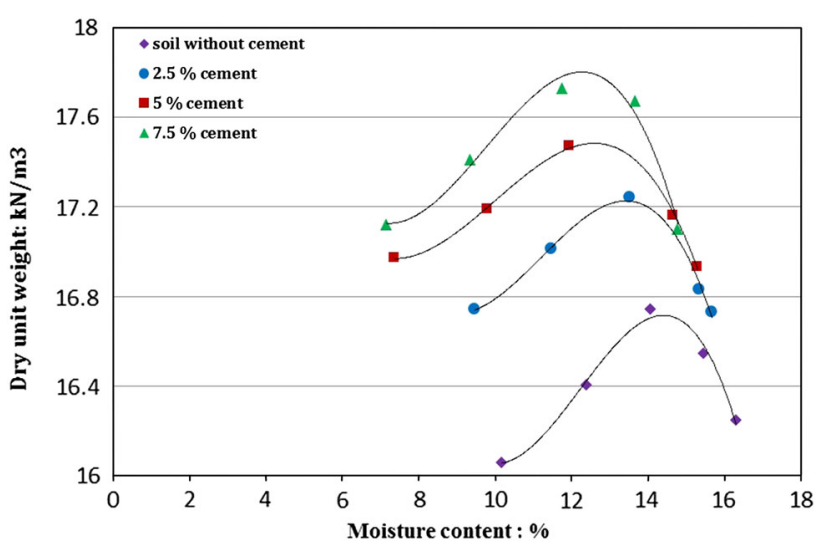

Fig. 3 Effect of cement stabilisation on compaction curves 


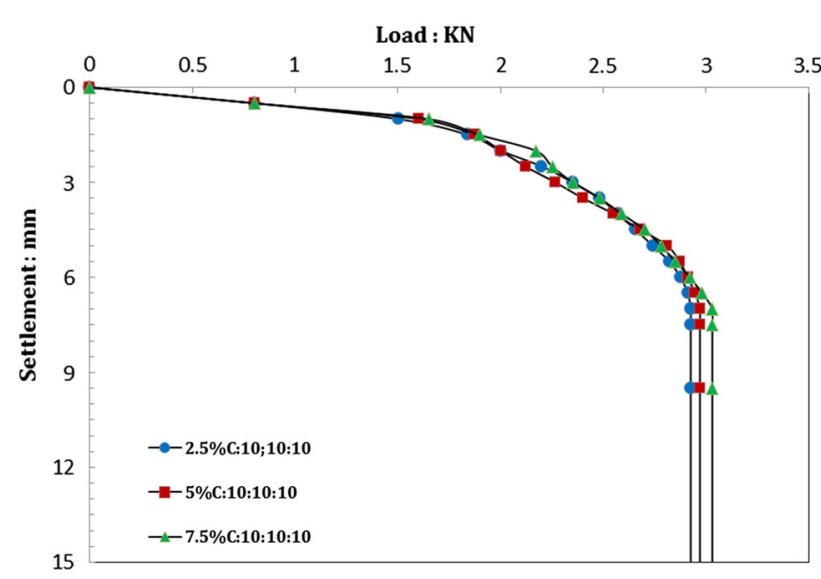

Fig. 4 Load-settlement curves in $10 \mathrm{~cm} \times 10 \mathrm{~cm} \times 10 \mathrm{~cm}$ samples with different cement content

Results show that under conditions of increased percentage of cement, evaluations for maximum dry unit weight increased and optimum moisture content decreased. Cement addition had an effect on compatibility of the soil-cement mixture. Changes in compaction parameters $\left(\gamma_{\text {dry }}\right.$ and $\left.\mathrm{w}_{\mathrm{opt}}\right)$ were affected by higher specific gravity value of cement compared to sand, alterations in grain size distribution of the mixture and reduction in moisture content [24,25]. The amount of alteration in $\gamma_{\text {dry }}$ was more enunciated at lower percentages of stabiliser.

\subsection{The Results of Plate Load Test}

The interpretation of the plate load test results was divided into three categories depending on the mechanism of the samples and their behaviour during the tests. A special abbreviation is used for better identification of each sample. The symbol A is the cement content (\%); B is the length of the sample; $\mathrm{C}$ is the width of the sample and; $\mathrm{D}$ is the thickness of the sample.

The ultimate load for cemented and uncemented soil can be obtained from the intersection of the tangents of the straight portions at the beginnings and ends of their respective load-settlement curves [26].

\section{2 .1 Results of Plate Load Test on $10 \mathrm{~cm} \times 10 \mathrm{~cm} \times 10 \mathrm{~cm}$ Samples}

Figure 4 shows the results of the plate load test on $10 \mathrm{~cm}$ $\times 10 \mathrm{~cm} \times 10 \mathrm{~cm}$ samples. As seen, each sample showed the same behaviour; the maximum load and the corresponding settlement were nearly identical for these samples. The behaviour of the samples was independent of their cement content.

The mechanism during the test was to make the samples infiltrate the soil after reaching a specified level of load. At

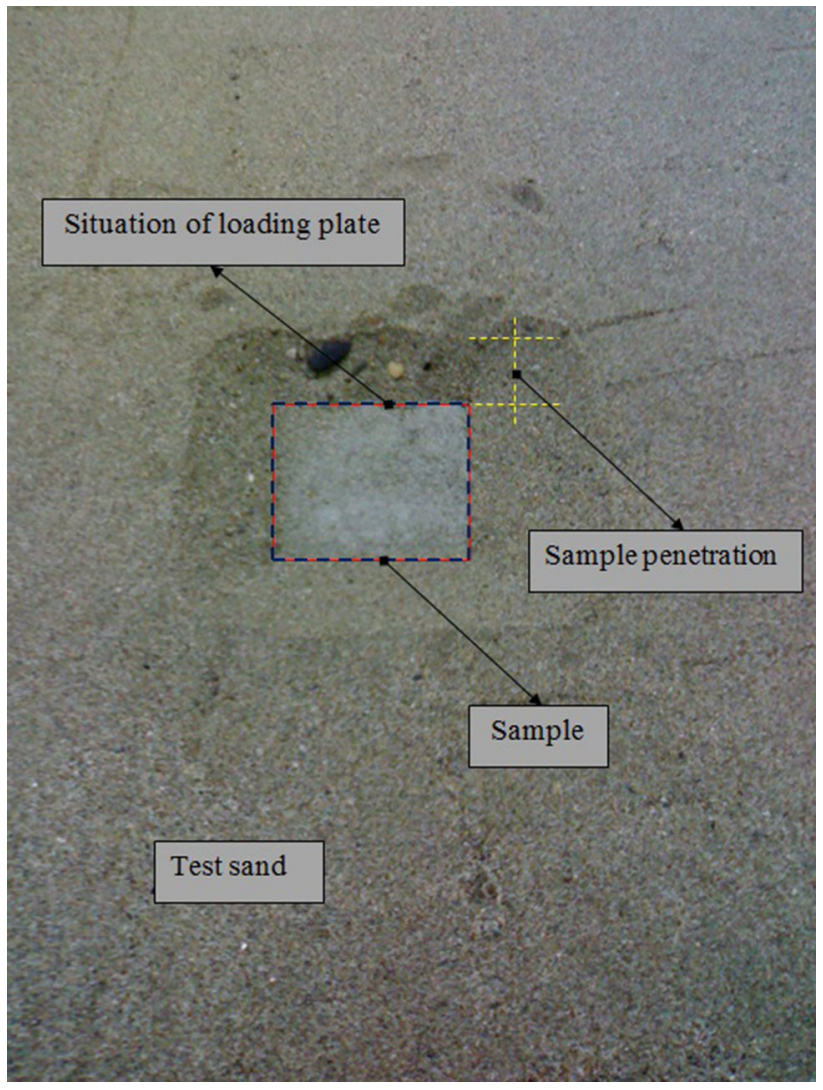

Fig. 5 Sample penetration into the soil

this point, when the load is constant, settlement increased (Fig. 4). This subject suggests a punching shear failure, because no lumps were observed around the samples at the end of testing (Fig. 5).

A summary of the results shows that one way to increase the bearing capacity of soil is to use stabilisation. It is important to assume that the dimensions of the foundation are the same as the dimensions of the stabilisation area so that there is no effect on the bearing capacity of the soil as the cement content increases. As described above, the samples penetrated the soil after reaching a specified load.

\subsubsection{Samples Containing 2.5\% Cement}

Figure 6 shows that, in samples with $2.5 \%$ cement, if the sample thickness was equal, increasing the area of the stabilised region had little effect on the bearing capacity of the soil.

In the initial stages of loading, the whole sample settled into the soil; then, when the load reached a specified level, the loading plate penetrated the sample. This process continued to the end of the test, indicating that settlement increased when loading was constant (Fig. 6).

If a low cement content is used to stabilise the soil beneath the foundation (here, $2.5 \%$ cement), increasing the dimen- 

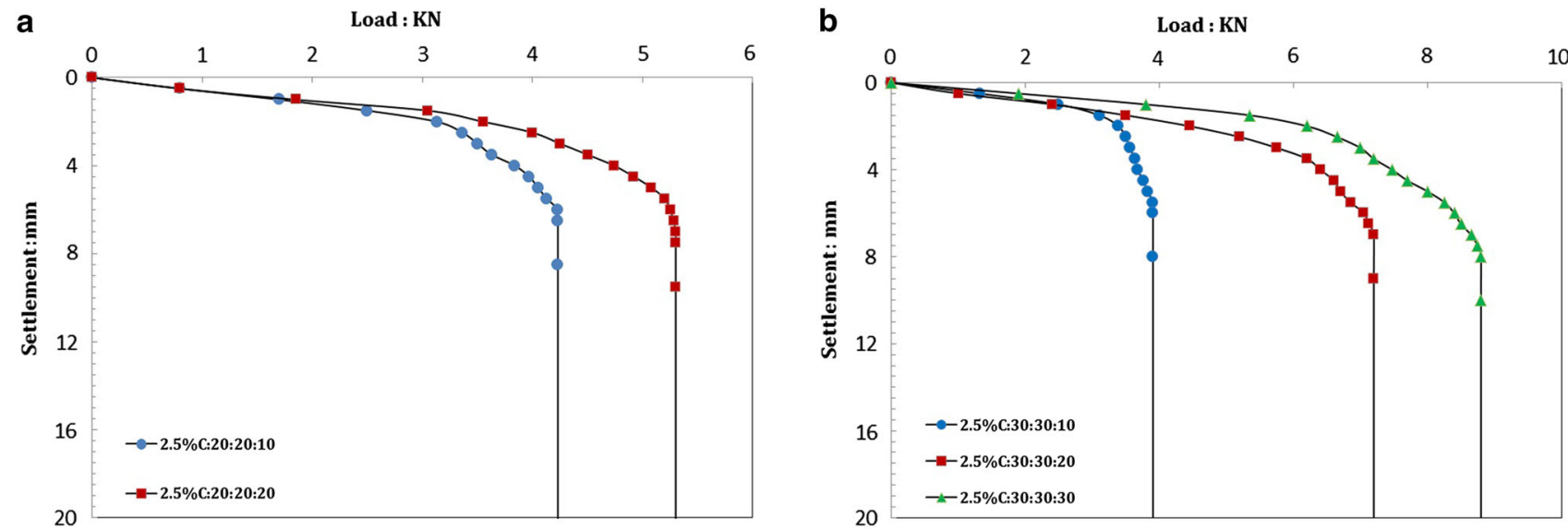

Fig. 6 Load-settlement curves in samples containing $2.5 \%$ cement with different thickness, a $20 \mathrm{~cm} \times 20 \mathrm{~cm}$ and $\mathbf{b} 30 \mathrm{~cm} \times 30 \mathrm{~cm}$ samples

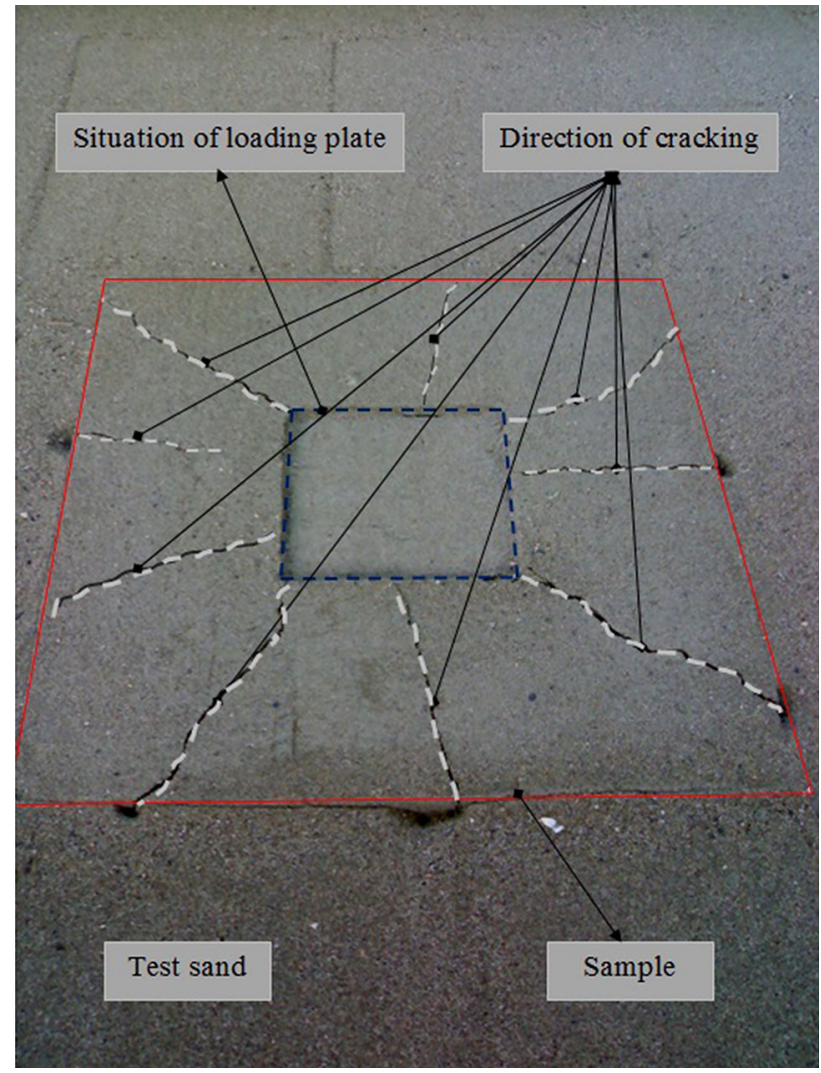

Fig. 7 Types of cracking observed in samples containing $2.5 \%$ cement

sions of the stabilised region has little effect on increasing the bearing capacity of the soil. The loading plate penetrated the sample after reaching a specified level of loading because the cement content was insufficient and the connections between the particles of soil were weak.

The types of cracking observed in samples containing $2.5 \%$ cement differ from those in samples containing 5 and $7.5 \%$ cement (which will be discussed at the next section). This difference is mainly in the number of cracks and the direction of cracking. Figure 7 shows that there are more cracks in samples with $2.5 \%$ cement than in other samples.

The direction of cracking is more irregular, which is related to the mechanism of the samples during testing. The loading plate penetrates the sample after reaching a certain level of force, causing diagonal cracks to appear. This is a result of the low cement content and the weak union between the particles of soil. Increasing the penetration of the loading plate increased the cracking (Fig. 7).

\subsubsection{Samples Containing 5 and $7.5 \%$ Cement}

Figures 8 and 9 show the results for samples with 5 and $7.5 \%$ cement. The result of plate load test on natural soil is shown in Fig. $9 \mathrm{~b}$ as a means of comparison for increasing the bearing capacity of soil.

In these samples, the whole sample settled into the soil after loading was applied, and this process continued to the end of testing and failure of the samples. Penetration of the loading plate into the soil was not observed because of the lack of a strong bond between the particles of soil, especially for samples containing $7.5 \%$ cement.

Figure 10 shows an increase in the thickness of the stabilised area in samples of equal dimensions where the increase in cement content increased the bearing capacity of the soil.

As shown in Fig. 11, $20 \mathrm{~cm} \times 20 \mathrm{~cm} \times 10 \mathrm{~cm}$ samples containing 5 and $7.5 \%$ cement showed more bearing capacity than the $30 \mathrm{~cm} \times 30 \mathrm{~cm} \times 10 \mathrm{~cm}$ samples containing the same cement content. This is a result of the greater rigidity of the $20 \mathrm{~cm} \times 20 \mathrm{~cm}$ samples than the $30 \mathrm{~cm} \times 30 \mathrm{~cm}$ samples of similar thickness $(10 \mathrm{~cm})$. This result was not observed for an increase in the thickness of these samples. In the other words, an increase in the dimension increased the bearing capacity of the soil at thicknesses of 20 and $30 \mathrm{~cm}$. 

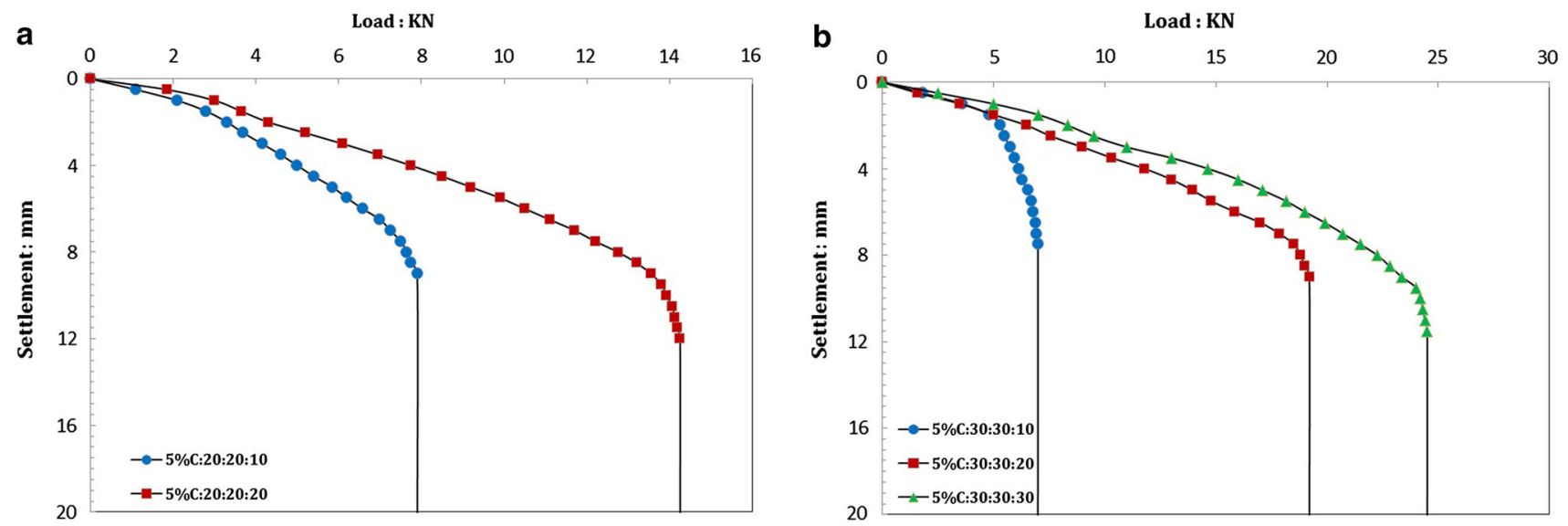

Fig. 8 Load-settlement curves in samples containing $5 \%$ cement with different thickness, a $20 \mathrm{~cm} \times 20 \mathrm{~cm}$ and b $30 \mathrm{~cm} \times 30 \mathrm{~cm}$ samples
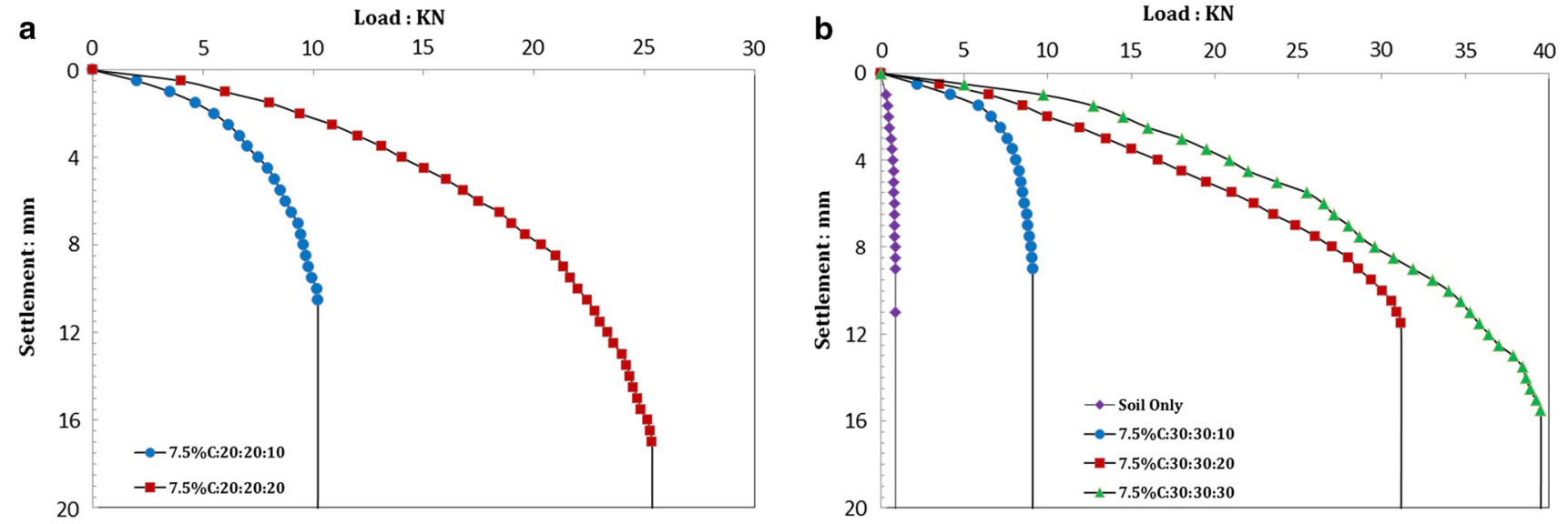

Fig. 9 Load-settlement curves in samples containing $7.5 \%$ cement with different thickness, a $20 \mathrm{~cm} \times 20 \mathrm{~cm}$ and $\mathbf{b} 30 \mathrm{~cm} \times 30 \mathrm{~cm}$ samples

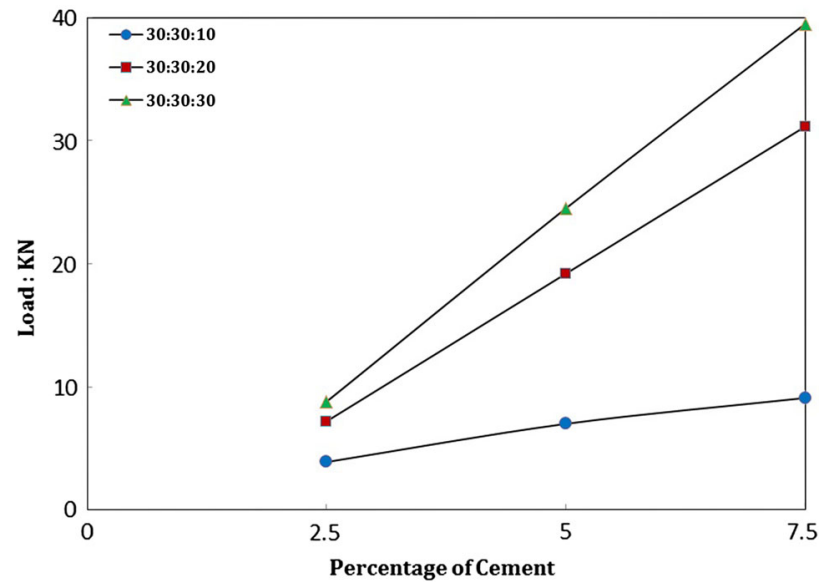

Fig. 10 Ultimate bearing capacity in $30 \mathrm{~cm} \times 30 \mathrm{~cm}$ samples with different thickness and cement content

Increasing the size of the stabilised area did not always increase the bearing capacity of the soil. It is necessary for engineers to decrease the cost and time before changing nec-

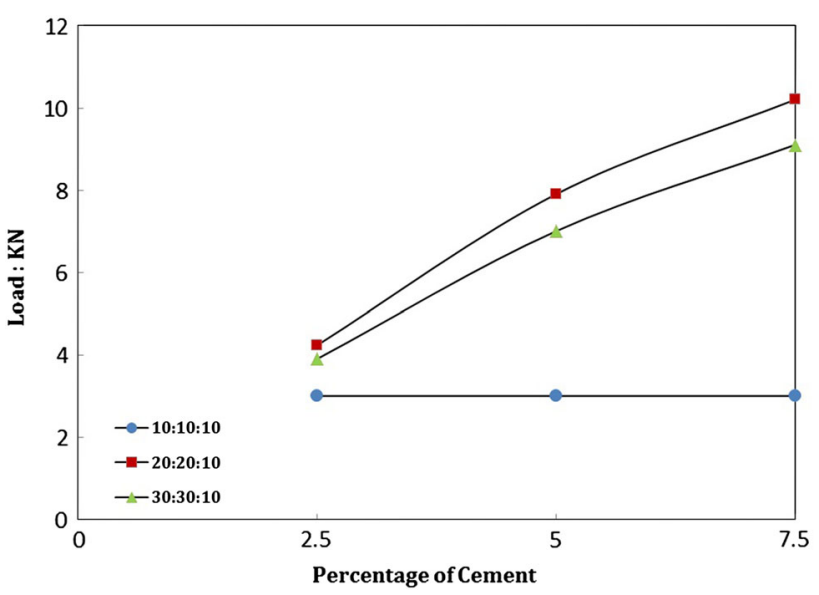

Fig. 11 Ultimate bearing capacity in samples with 10 -cm-thick and different dimensions versus cement content

essary considerations like the amount of bearing capacity and the dimensions of a well-stabilised area.

After the end of testing, failure of samples with 5 and $7.5 \%$ of cement content was observed through boreholes excavated 


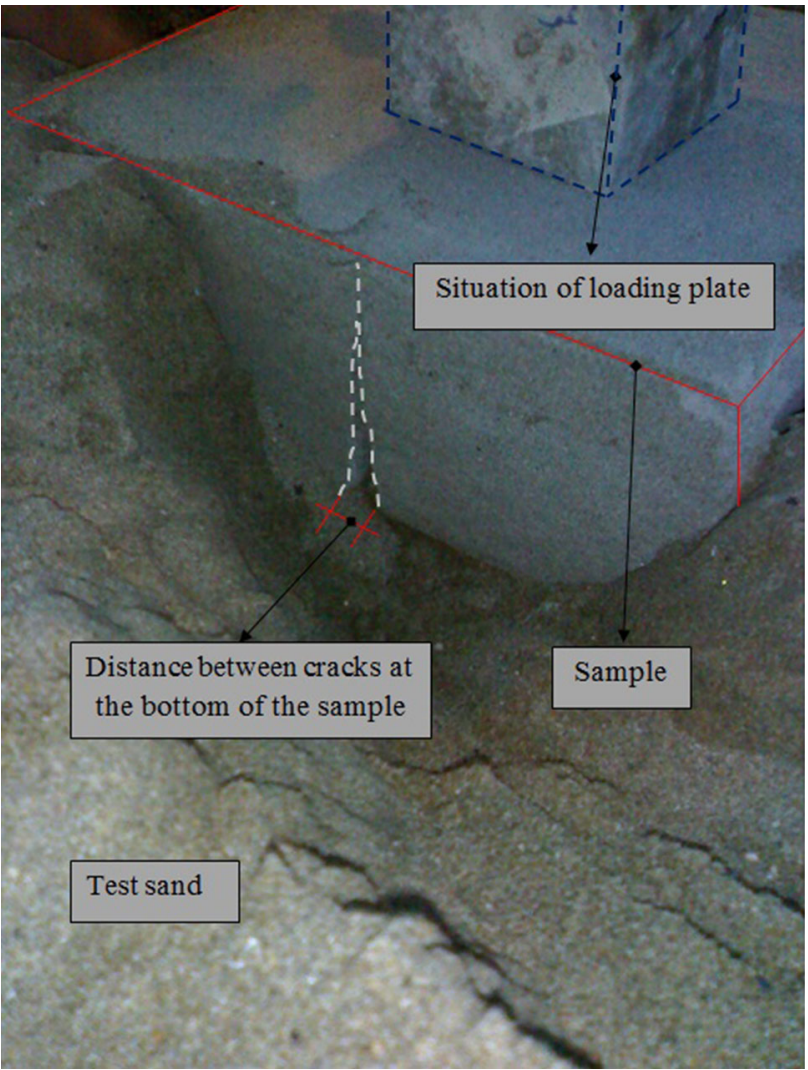

Fig. 12 Tensile cracks in $30 \mathrm{~cm} \times 30 \mathrm{~cm} \times 10 \mathrm{~cm}$ sample with $7.5 \%$ cement

in the form of tensile cracks spreading from bottom to top of the samples. This resulted in larger cracks at the bottom of the samples. Figure 12 shows that the $30 \mathrm{~cm} \times 30 \mathrm{~cm} \times 10$ $\mathrm{cm}$ sample contains $7.5 \%$ cement and clearly demonstrates this condition. These conclusions agree well with published data for this type of soil [9].

The types of cracks observed in the samples containing 5 and $7.5 \%$ cement differ in mechanism from cracks observed in samples containing $2.5 \%$ cement (Fig. 7). Figures 13 and 14 indicate that the greater the cement content, the more regular is the cracking. The cracks observed in samples containing $7.5 \%$ cement (Fig. 14) are more regular than those observed in the sample containing $5 \%$ cement (Fig. 13). The cracks appear perpendicularly in the middle of the sample. The occurrence of vertical cracking in the middle of the sample is a result of the principle of strength of materials and is based on the maximum stress in the middle of rectangular samples.

\section{Load-Time Curve}

The loading plate test was the chosen method of strain control in this study. Standards require that the amount of load

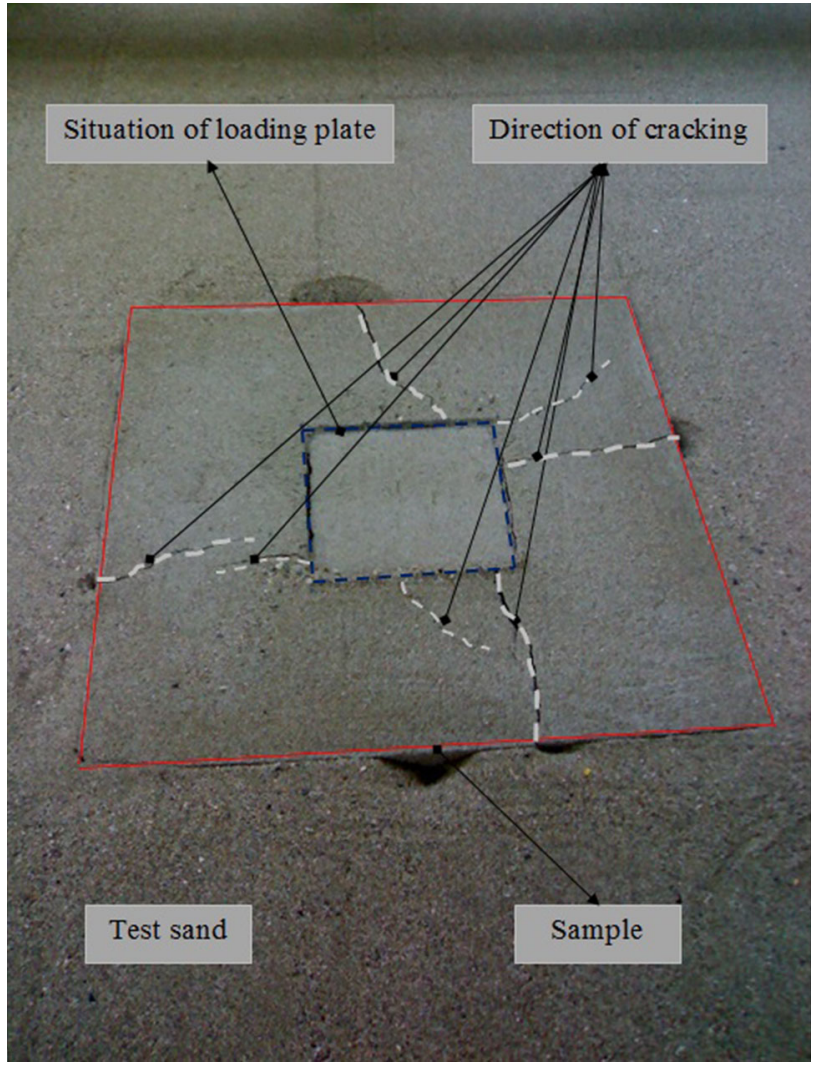

Fig. 13 Types of cracking observed in samples containing $5 \%$ cement

must be recorded for $0,0.5,1,2,4,8$ and 15 min after load application until the amount of load is constant. If a constant load is not reached, more time can be used to fix the load. It is important to note that the time pattern used to record the amount of load must be applied at all stages of loading.

Figure 15 demonstrates that, for samples with $7.5 \%$ cement content, a longer time interval was recorded for each settlement increment. The selected time interval $(15 \mathrm{~min})$ was appropriate for the samples with 2.5 and $5 \%$ cement content. There were a large number of curves in this section, but the variation in curves was similar; thus, only the load-time curve for the eighth settlement increment is shown.

To eliminate the effect of the magnitude of loading on the load-time curve, the loads for samples with 5 and $7.5 \%$ cement contents were divided into the loads for samples with $2.5 \%$ cement content. These values are recorded at the end of each increment of applied load (Fig. 16).

The different loads were recorded for each settlement increment. The loading for samples containing $2.5 \%$ cement was less than that for samples containing 5 and $7.5 \%$ cement. In the $2.5 \%$ samples, part of the load dissipated because the loading plate penetrated the samples; they were less rigid than the 5 and $7.5 \%$ samples. This is also the reason for the difference in loading in samples containing 5 and $7.5 \%$ cement. 


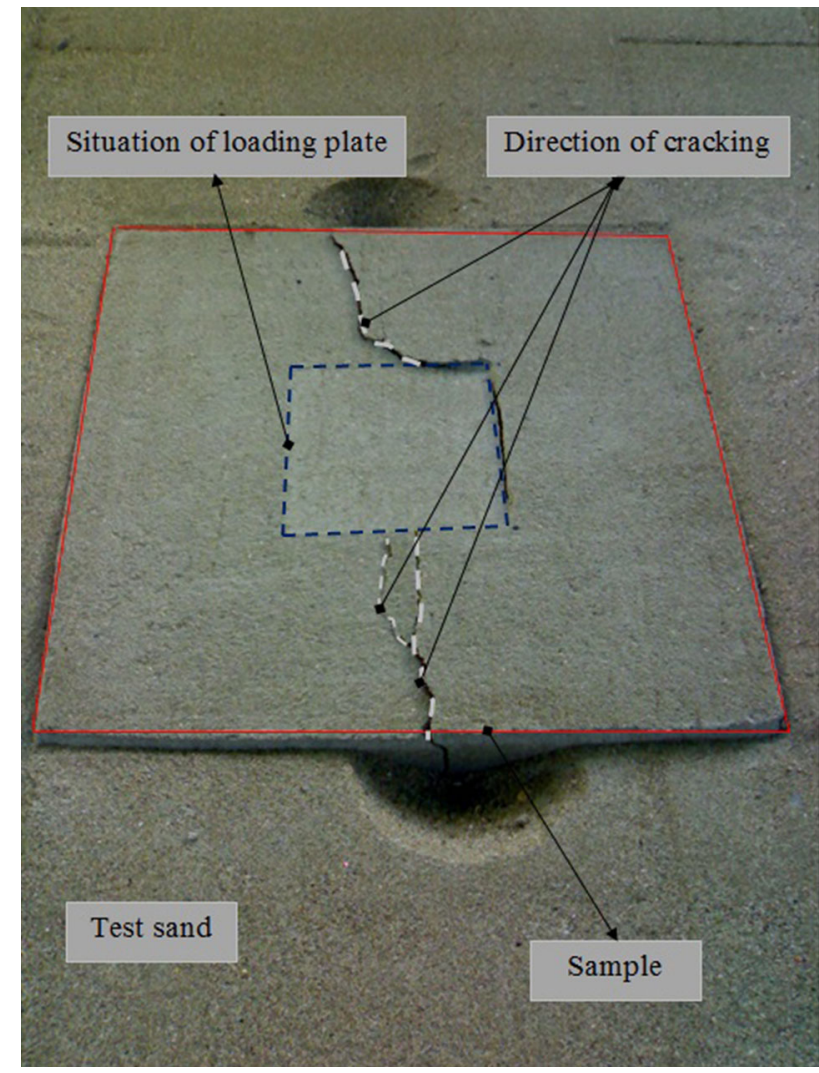

Fig. 14 Types of cracking observed in samples containing $7.5 \%$ cement

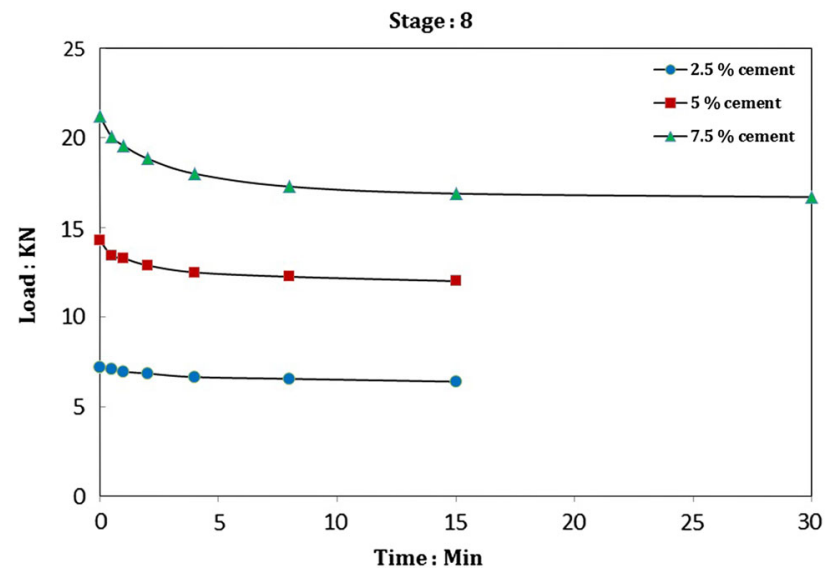

Fig. 15 Load-time curve in $30 \mathrm{~cm} \times 30 \mathrm{~cm} \times 20 \mathrm{~cm}$ samples with different cement content related to eighth settlement increment

\section{Conclusions}

Soil stabilisation with cement is a way to increase the bearing capacity of soil. The following conclusions can be drawn from the testing carried out in this study:

1. Increasing the cement content and the dimensions of the stabilised region increases the bearing capacity of the soil.

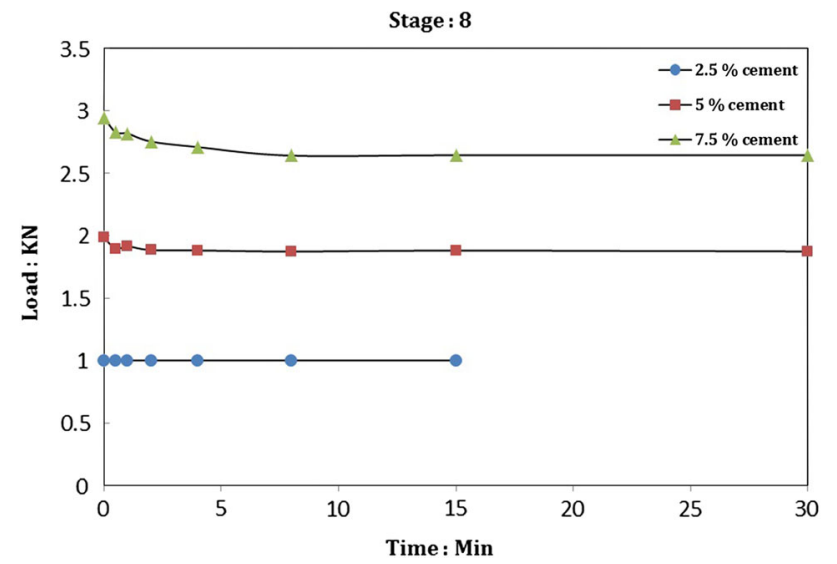

Fig. 16 Normalised load-time curve related to eighth settlement increment

2. The behaviour of the $10 \mathrm{~cm} \times 10 \mathrm{~cm} \times 10 \mathrm{~cm}$ samples was independent of their cement content. Each of these samples showed the same behaviour; the maximum load and the corresponding settlement were nearly identical.

3. In samples with $2.5 \%$ cement, if the sample thickness was equal, increasing the area of the stabilised region had little effect on the bearing capacity of the soil.

4. Increasing the size of the stabilised area did not always increase the bearing capacity of the soil. For example, $20 \mathrm{~cm} \times 20 \mathrm{~cm} \times 10 \mathrm{~cm}$ samples containing 5 and $7.5 \%$ cement showed more bearing capacity than the $30 \mathrm{~cm}$ $\times 30 \mathrm{~cm} \times 10 \mathrm{~cm}$ samples containing the same cement content.

5. The types of cracking observed in samples containing $2.5 \%$ cement differ from those in samples containing 5 and $7.5 \%$ cement. This difference is mainly in the number of cracks and the direction of cracking. The cracks observed in samples containing $7.5 \%$ cement were more regular than those observed in the sample containing 2.5 and $5 \%$ cement

6. Increasing the cement content increases the brittleness of the soil. This can be understood by comparing the mechanism of cracking in Figs. 7, 13 and 14. Fragility can cause the sudden failure of structures in which cement has been used for stability. It may not be possible to use stabilisation for major structures, especially in shallow parts because of low confining pressure.

7. In samples with $7.5 \%$ cement content, a longer time interval was recorded for each settlement increment. The selected time interval $(15 \mathrm{~min})$ was appropriate for the samples with 2.5 and $5 \%$ cement content.

Acknowledgments The authors wish to express their gratitude to Babol University of Technology for their financial support and the dedicated aids of the technicians at the laboratory of this university. 
Open Access This article is distributed under the terms of the Creative Commons Attribution License which permits any use, distribution, and reproduction in any medium, provided the original author(s) and the source are credited.

\section{References}

1. Engineering Manual 1110-3-137.: Soil Stabilisation for Pavement Mobilization Construction. Department of U.S Army Corps of Engineers, Washington D.C (1984)

2. Aiban, S.A.: A study of sand stabilisation in eastern Saudi Arabia. Eng. Geol. 38, 65-79 (1994)

3. Sitar, N.: Slope stability in coarse sediments. In: Special Publication on Geological Environment and Soil Properties, ASCE., pp. 82-98 (1983)

4. Consoli, N.C.; Vendruscolo, M.A.; Fonini, A.; Rosa, F.D.: Fiber reinforcement effects on sand considering a wide cementation range. Geotext. Geomembr. 27, 196-203 (2009)

5. Stefanoff, G.; Jellev, J.; Tsankova, N.; Karachoron, P.; Slavov, P.: Stress and strain state of a cement-less cushion. In: Proceeding VIII European Conference of Soil Mechanics and Foundation Engineering, Helsinki., pp. 811-816 (1983)

6. Al-Sanad, H.A.; Ismael, N.F.; Brenner, R.P.: Settlement of circular and ring plates on very dense calcareous sand. J. Geotech. Eng. 119(4), 622-638 (1993)

7. Ismael, N.F.; Al-Sanad, H.A.: Plate load tests on weakly cemented surface desert sands. Geotech. Eng. 24(2), 133-150 (1993)

8. Ismael, N.F.: Loading tests on circular and ring plates in very dense cemented sands. J. Geotech. Eng. ASCE 122(4), 281-287 (1996)

9. Consoli, N.C.; Vendruscolo, M.A.; Prietto, P.P.M.: Plate load tests on soil layers improved with cement and fiber. J. Geotech. Geoenviron. Eng. ASCE 129(1), 96-101 (2003)

10. Thome, A.; Donato, M.; Consoli, N.C.; Graham, J.: Circular footing on a cemented layer above weak foundation soil. Can. Geotech. J. 42, 1569-1584 (2005)

11. Consoli, N.C.; Thome, A.; Donato, M.; Graham, J.: Loading tests on compacted soil bottom ash and lime layers. Proc. Inst. Civil Eng. Geotech. Eng. 169, 29-38 (2007)

12. Consoli, N.C.; Rosa, F.D.; Fonini, A.: Plate load tests on cemented soil layers overlying weaker soil. J. Geotech. Geoenviron. Eng. ASCE 135(12), 1846-1856 (2009)
13. Bowles, J.E.: Foundation Analysis and Design, vol. 1175. Mc Graw-Hill Publishing (1996)

14. Das, B.M.: Shallow Foundation: Bearing Capacity, vol. 384. CRC Press (1999)

15. ASTM D 421.: Standard Practice for Dry Preparation of Soil Samples for Particle-Size Analysis and Determination of Soil Constant. Annual Book of ASTM Standards, American Society for Testing and Materials, West Conshohocken., pp. 1-2 (2002)

16. ASTM D 422.: Standard Test Method for Particle-Size Analysis of Soils. Annual Book of ASTM Standards, American Society for Testing and Materials, West Conshohocken., pp. 1-8 (2003)

17. ASTM D 2487.: Standard Classification of Soils for Engineering Purposes. Annual Book of ASTM Standards, American Society for Testing and Materials, West Conshohocken., pp. 1-12 (2006)

18. Institute of Standards and Industrial Research of Iran, ISIRI 4220

19. ASTM D 698.: Standard Test Method for Laboratory Compaction Characteristics of Soil Using Standard Effort. Annual Book of ASTM Standards, American Society for Testing and Materials, West Conshohocken., pp. 1-11 (2000)

20. Ladd, R.S.: Preparing test specimen using undercompaction. Geotech. Test. J. 1(1), 16-23 (1978)

21. Baldi, G.; Heigt, D.W.; Thomas, G.E.: A reevaluation of conventional triaxial test methods. In: Donaghe, R.T.; Change, R.T.; Silver, M.L.; Advanced Triaxial Testing of Soil and Rock, ASTM, S.T.P., vol. 977, pp. 219-263 (1988)

22. ASTM D 1556.: Standard Test Method for Density and Unit Weight of Soil in Place by the Sand-Cone Method. Annual Book of ASTM Standards, American Society for Testing and Materials, West Conshohocken., pp. 1-7 (2000)

23. ASTM D 1194.: Standard Test Method for Bearing Capacity of Soil for Static Load and Spread Footings. Annual Book of ASTM Standards, American Society for Testing and Materials, West Conshohocken., pp. 1-3 (1994)

24. Zabielska, K.: Laboratory compaction of fly ash and fly ash with cement additions. J. Hazard. Mater. 151, 481-489 (2008)

25. Al-Aghbari, M.Y.; Mohamedzein, Y.E.A.; Taha, R.: Stabilisation of desert sands using cement and cement kiln dust. Proc. Inst. Civil Eng. Ground Improv. 162, 145-151 (2009)

26. Adams, M.T.; Collin, J.G.: Large model spread footing load tests on geosynthetic reinforced soil foundations. J. Geotech. Geoenviron. Eng. ASCE 123(1), 66-72 (1997) 